\title{
Technical and Economic Assessment of Storage Technologies for Power-Supply Grids
}

\begin{abstract}
H. Meiwes
Fluctuating power generation from renewable energies such as wind and photovoltaic are a technical challenge for grid stability. Storage systems are an option to stabilise the grid and to maximise the utilisation factors of renewable power generators. This paper analyses the state of the art of storage technologies, including a detailed life cycle cost comparison. Beside this, benefits of using storage systems in electric vehicles are analysed and quantified. A comprehensive overview of storage technologies as well as possible applications and business cases for storage systems is presented.
\end{abstract}

Keywords: Storage systems, batteries, renewable energies, grid stability, vehicle to grid, life cycle cost.

\section{Introduction}

National and European energy policies aim at an increasing contribution from renewable sources. The European Commission's target for this contribution is $20 \%$ by 2020. For Germany, with its already existing high amount of onshore wind turbines, the most probable growth is seen in wind energy at offshore locations and repowering of existing onshore sites.

A major obstacle for a further increasing contribution from these renewable sources lies in their intermittent nature and thus in their undetermined availability. Reported durations of unavailability of power produced in onshore wind turbines can reach up to some weeks under special weather conditions, and are not locally restricted. Today, conventional power plants are needed in order to adapt the electricity generation at each moment to the existing load and to cover the periods of unavailability of wind and solar energy. As a consequence, conventional thermal power plants have to provide an increasing amount of control power and thus frequently operate at inefficient partial load or have to shut down.

In this situation the operation of energy storage systems can help to allow a higher amount of renewable energy sources (RES) by stabilizing the grid and finally decreasing the consumption of fossil fuels. As a result, the emissions of conventional fossil fired thermal power plants can be reduced and the remaining thermal power plants can operate more continuously and close to their best efficiency.

In principle, pumped hydro storage plants are particularly suitable for the supply of control and reserve power. However, their current capacity cannot readily be expanded significantly because of geographic constraints. It is beyond all question to cover the long periods of unavailability of wind energy by pumped hydro plants of the conventional type. Having in mind the huge amount of needed storage capacity, other possibilities for energy storage systems such as compressed air energy storage (CAES) or the possibilities of hydrogen production and storage have to be investigated.

Economically, these storage systems generally compete with fast acting conventional generation technologies, e.g. gas turbines. At the present time, it seems very difficult to justify the need for large scale energy storage from a purely economic point of view. However, it could be argued that external effects such as the ecological and overall national socio-economic benefits of storage systems (e.g. reduction of $\mathrm{CO}_{2}$-emissions or the possibility to reduce dependency on energy imports) should also be taken into account. The high prices paid today for primary, secondary and minute reserve already indicate an economic potential for storage systems.

A further future market for energy storage applications can be expected in the transportation sector. The fuel stored in today's car and truck fleet represents an enormous potential to be replaced by batteries (plug-in hybrid vehicles) or hydrogen storage (with re-electrification in fuel cells) in future. Unlike hydrogen vehicles, plug-in hybrids do not require an extensive new infrastructure. Nevertheless, also here technological and economic barriers need to be overcome before a mass market roll-out can take place. As long as these mobile storage systems are connected to the grid they are in principle also able to provide grid services, if controlled by a suitable management system. A significant number of plug-in hybrids being on the market may replace some stationary storage systems. A few numbers show the potential of the vehicle-to-grid scenario: Just $10 \%$ of the German cars equipped as plug-in hybrids (10 kWh storage, $5 \mathrm{~kW}$ bi-directional charger) account for $20 \mathrm{GW}$ well distributed installed power for 2 hours.

\section{Characterisation of energy storage systems}

Energy storage systems can be characterized by a set of parameters. For the selection of a suitable energy storage system it is necessary to know as exactly as possible the characteristics of typical duty cycles, their frequency and the required response time to full power. In this context the load following capability and the power-flow reversal (e.g. change from charging to discharging) may also become important for certain applications. This data defines the energy throughput and the number of cycles per time unit. The efficiency of storage systems can be described by their cycle losses and stand-by losses (including the power conversion system and 
auxiliaries). It is necessary to note that the efficiency depends for many storage technologies on the duty cycle. For all electrochemical systems, efficiency decreases with increasing charge/discharging power rate.

Concerning the investment costs, a distinction has to be made between power-dependent costs and capacity dependent costs. Regarding the latter, attention has to be paid to the fact that a difference generally exists between the gross energy content and the usable energy content. For compressed-air storage systems based on caverns, a limitation for the usable energy content also exists depending on the duty cycles and their frequency. The depth of discharge (DOD) may have an influence on the lifetime, e.g. for batteries. For the various main components of a storage system, different lifetimes have generally to be considered as well as reliability and maintenance aspects.

In addition to electrical parameters other characteristics like weight, footprint, volume, transport logistics, auxiliaries, and environmental aspects are also decision making factors.

\section{Storage technologies}

Storage technologies can be distinguished according to Tab. 1 into three major groups with different features. The main characteristics and features of the different storage technologies are discussed below.

There is over $90 \mathrm{GW}$ of pumped hydro storage in operation worldwide, which is about $3 \%$ of global power generation capacity. Pumped storage plants are characterized by long construction times and high capital expenditure. Pumped storage is the most widespread energy storage system in use on power grids, and is commercially available from many manufacturers. However, a large percentage of pumped hydroelectric potential has already been developed in North America and Europe. Typical applications of pumped hydro power plants are secondary and minute reserve, peak shaving, or Load-leveling, and they have black-start capabilities. The typical efficiency range is 65-80\%, strongly dependent on the site. Depending on the size of the lake, typical discharge durations realized today are in the range of a few hours. The power range is $10 \mathrm{MW}$ to $1 \mathrm{GW}$ and the time to full power is in the order of $90 \mathrm{~s}[1,2]$.
Compressed air energy storage (CAES) has similar properties as pumped hydro, but with other geographic restrictions as cavern leaching needs suited salt deposits in the underground. Existing 'diabatic' CAES plants can be thought of as gas turbine plants, where the compression process and the expansion process are temporally decoupled: excess electricity is used to drive turbo-compressors that fill underground caverns with compressed air (cooled down to $\sim 50{ }^{\circ} \mathrm{C}$ ). At times of peak load, compressed air is drawn from the cavern, then heated in gas burners and expanded in a modified gas turbine. As a drawback, the cycle still depends on fossil fuel and also has limited cycle efficiency due to the waste heat emerging from the compression process. Improved implementation makes use of the gas turbine waste heat with the help of a recuperator in the fuel gas path. However, the system inherent limitation of the efficiency remains. Adiabatic CAES, a novel concept, seeks to overcome these disadvantages by re-incorporating the otherwise lost compression heat into the expansion process and thus to provide a locally emission-free storage technology with high storage efficiency. It thus needs heat storage as a central element of the plant. So far, adiabatic CAES are a subject of research, while diabatic CAES technology is commercially available from several manufacturers. The multitude of suitable sites for CAES is a beneficial condition for broad introduction on the market. A typical pressure is in the range of 6-10 MPa. For daily cycling the usable pressure swing has to be limited to approx. $2 \mathrm{MPa}$. The round-trip efficiency is in the range of $42-54 \%$ for a diabatic CAES and up to $70 \%$ for an adiabatic CAES. Depending on the size of the cavern, discharge durations from a few hours up to a few days are possible. The time to full power is in the range of 15 minutes, which is sufficient for providing minutes reserve [3].

Hydrogen can be produced from power by high pressure electrolysers (pressures between 3 and probably $20 \mathrm{MPa}$ ). Various electrolyser technologies are under development. For efficient storage hydrogen has to be compressed further before being stored in underground salt caverns at a pressure of up to $20 \mathrm{MPa}$ and above. As charging and discharging is slow, a pressure swing of about 2/3 can be realized. For high power levels the most efficient conversion back to electricity can be achieved in combined cycle power plants. In the lower power

Table 1: Overview on storage applications and suited storage technologies

\begin{tabular}{|c|c|c|c|c|}
\hline & Response Time & $\begin{array}{c}\text { Typical discharge } \\
\text { times }\end{array}$ & Storage technologies & Suited applications \\
\hline X-Large Scale & $>15 \mathrm{~min}$ & days - weeks & Hydrogen storage systems & $\begin{array}{l}\text { reserve power compensating } \\
\text { for long-lasting unavailability } \\
\text { of wind energy }\end{array}$ \\
\hline Large Scale & $<15 \min$ & hours - weeks & $\begin{array}{l}\text { Compressed air storage } \\
\text { (CAES) } \\
\text { Hydrogen storage systems } \\
\text { Pumped hydro }\end{array}$ & $\begin{array}{l}\text { secondary reserve } \\
\text { minute reserve } \\
\text { Load-leveling }\end{array}$ \\
\hline Medium Scale & $1-30 \mathrm{~s}^{1)} / 15 \mathrm{~min}^{2)}$ & $\min -$ hours & $\begin{array}{l}\text { Batteries (Li-Ion, lead-acid, } \\
\text { NiCd) } \\
\text { High-temp. batteries } \\
\text { Zinc-bromine batteries } \\
\text { Redox-flow batteries }\end{array}$ & $\begin{array}{l}\text { primary reserve }^{1)} \\
\text { secondary \& minute reserve }^{2)} \\
\text { Load-leveling, peak shaving }\end{array}$ \\
\hline
\end{tabular}


range fuel cells can be applied. Round-trip efficiencies are expected to be in the range of $35-40 \%$. The power range is $10 \mathrm{~kW}$ to $1 \mathrm{GW}$ and the ramp-up time is about 1 to 5 minutes. The achievable energy density of compressed hydrogen is more than one order of magnitude higher than the one of compressed air. Storage of compressed hydrogen in salt caverns is relatively cheap, which qualifies this technology especially for long-term storage of bulk energy to be reused during long-lasting unavailability of wind energy. It is currently the only technology with a technical potential for single storage systems in the $100 \mathrm{GWh}$ range $[4,5]$.

The lead-acid battery is one of the oldest battery technologies and today still the most used secondary battery technology worldwide. Lead-acid batteries are commercially available from many manufacturers all over the world, and there are also large scale installations in the $10 \mathrm{~kW}$ to $50 \mathrm{MW}$ class which have been in operation in the past 25 years. Their biggest advantage is the low cost compared to other storage systems. However, lead-acid batteries for large stationary applications are not produced in large quantities of one cell type in fully automated production lines as they are used today for automotive batteries to achieve sufficient economy of scale effects. Therefore, especially for large scale applications, there is still room for cost reductions and also for technical improvements with regard to lifetime. The typical efficiency range is $80-85 \%$. The lead-acid battery is more a high energy technology rather than a high power technology, which means typical discharge durations in the range of 1 hour and more. Discharge durations below $15 \mathrm{~min}$ are possible but generally make no sense. The available capacity decreases significantly with increasing discharge current rates. Lead-acid batteries suffer especially from their short life-time, limited usually to a few thousand cycles and depending strongly on the DOD [6].

Nickel-cadmium batteries are a very successful battery product from a technical point of view and this is the only battery technology that still features a good power capability for temperatures in the range of -20 to $-40{ }^{\circ} \mathrm{C}$. Large battery systems built from NiCd batteries are in operation, similar to those for lead-acid batteries. The specific costs per capacity are significantly higher compared with lead-acid batteries, but they can provide a long cycle lifetime with more than 10.000 cycles at $80 \%$ DOD. A small number of manufacturers deliver industrial NiCd batteries in the world. There are several technology variants available for optimization adapted to specific requirements (lifetime, cycle number and power requirement). The use of cadmium is critical and, therefore, this technology is on the inspection list of the EU preceding possible prohibition, which can only be impeded as long as there are no alternative storage technologies available. The efficiency of NiCd batteries is about $70 \%$ due to the low nominal voltage of the basic cells [7].

Lithium-ion batteries have become the most important storage technology in portable applications (e.g. laptops, cell phones) within a few years, due to their high gravimetric energy density. Also in stationary applications, they could be an interesting option because of their high power capability. Recent developments underline the future potential of this technology. Discharge times of 15 minutes or less are possible. Unlike other secondary battery technologies, a large variety of material combinations are available for lithium-ion batteries.
On the one hand, this makes it difficult to give some general statements on the performance; on the other hand it gives room for numerous companies and players in the field and for strong competition among companies and technologies. Worldwide investments in R\&D of more than 500 million US $\$$ per year are being spent to bring the technology forward for portable, stationary and mobile (hybrid, plug-in hybrid and full electric vehicles) applications. The efficiency is 90 to $95 \%$, and the gravimetric energy density is superior to all other commercial rechargeable batteries in the capacity range of kWh and above. [6, 8]

Sodium-Nickel-Chloride- (NaNiCl, also called Zebra-battery) and Sodium-Sulphur-batteries (NaS) have a solid state instead of a liquid electrolyte like other batteries. To achieve sufficient ion conductivity and to transfer the active masses into fluid condition, an operation temperature of $270-350{ }^{\circ} \mathrm{C}$ is necessary. When the battery is cooled down, charging or discharging is no longer possible, and there is the danger of cracks in the ceramic electrolyte because of mechanical tensions. For daily utilization, the temperature of the battery can be maintained by its own reaction heat with an appropriately dimensioned isolation. Thereby these batteries qualify for applications with daily cycling. In Japan, NaS batteries are commercially available and are used in many stationary applications such as load-leveling, sometimes including emergency power supply and UPS. NaNiCl batteries are commercially available in Europe mainly for mobile applications such as full electric vehicles. The efficiency is 70-80\%. High temperature batteries are typical high energy batteries $[6,9]$.

In redox-flow batteries, the active material is made up of salt, which is dissolved in two different fluid electrolytes. The electrolytes are stored in tanks and are pumped, when needed, into a central reaction unit (stack) for the charge or discharge process. Similar to fuel cells, the stack undergoes no physical or chemical change during the charge/discharge process. The size of the tank determines the energy capacity of the battery; the stack determines the power. Principally, this battery technology is very well suited for large-scale application because bigger tanks can be constructed very easily and effectively. Important combinations of salts, which are under investigation, are e.g. $\mathrm{NaBr}+\mathrm{Na}_{2} \mathrm{~S}_{4} / \mathrm{Na}_{2} \mathrm{~S}_{2}+\mathrm{NaBr}_{3}$ (Regenesys), $\mathrm{Fe} / \mathrm{Cr}, \mathrm{Br}_{2} / \mathrm{Cr}$ or Vanadium. Among these, the all-vanadium redox-flow battery is particularly interesting, because the same material is used for both electrodes. They are meanwhile commercially available from two or three manufacturers. In Japan, installations have already been built and operated for years for load-leveling applications. Other material combinations are still on the level of research. The system efficiency (including energy consumption of pumps, etc.) of most systems is in the range of 60 to $75 \%$. Redox-flow batteries are a typical high energy battery and are less suited for power applications with discharge times below one hour [10].

Zinc/bromine batteries are similar to redox-flow batteries. The battery consists of a zinc negative electrode and a bromine positive electrode separated by a micro porous separator. An aqueous solution of zinc/bromide is circulated through the two compartments of the cell from two separate reservoirs. Zinc is deposited in the stack during operation. This is a major difference to redox-flow batteries, where the stacks themselves remain unchanged during charging and 
discharging. The zinc/bromine battery can be repeatedly fully discharged without any damage to the battery. The zinc/bromine battery is predominantly made with low cost, recyclable plastics and manufactured with techniques suitable for mass production and at low production costs. Today only one company is actively developing and supplying zinc/bromine batteries. The zinc bromine energy storage system is now in the first stages of commercialization. There are already some stationary installations. The performance of zinc bromine batteries is similar to redox-flow batteries; the efficiency at high rates is lower [11].

\section{Economic assessment and discussion}

When evaluating the most suited storage technologies, it is necessary to make a precise definition of the boundary conditions in terms of power, energy, response time and capital costs to achieve comparable results. Three classes of storage applications are discussed in this paper with regard to suited storage technologies and cost estimations:

A) Long-term storage (500 MW, $100 \mathrm{GWh}, 200 \mathrm{~h}$ full load, $\sim 1.5$ cycle per month)

B) Load-Leveling (1 GW, 8 GWh, 8 h full load, 1 cycle per day)

C) Peak-Shaving at distribution level (10 MW; $40 \mathrm{MWh}$, $4 \mathrm{~h}$ full load, 2 cycles per day)

A life cycle cost (LCC) analysis has been performed for different storage technologies with respect to the three application classes. Each application is defined by the required charge/discharge power, the necessary energy content (resulting in the effective gross energy content of the storage), the number of cycles per day and the required overall system lifetime. If a storage technology is not able to achieve the required system lifetime, the storage system or the relevant subsystems are assumed to be replaced and the costs are accounted accordingly. The LCC takes into account investment costs for the storage medium itself, including the necessary auxiliaries and the power interfaces for charging and discharging, resulting in corresponding capital costs. The lifetime - for some technologies depending on the cycle depth - is also taken into account as well as costs for buying

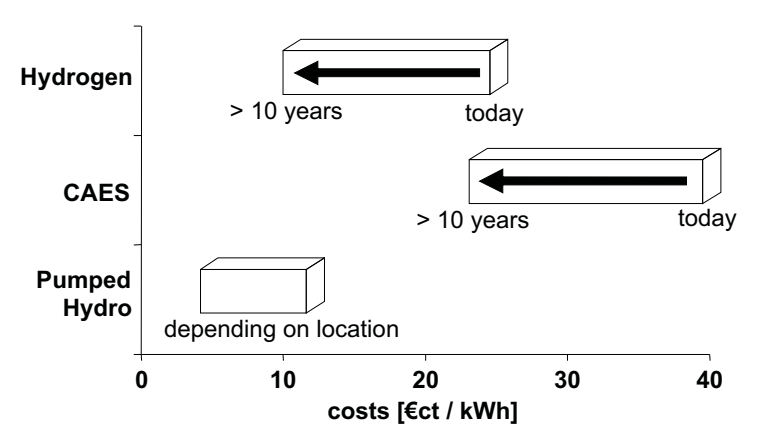

Fig. 1: Comparison of storage systems for long-term storage, class A

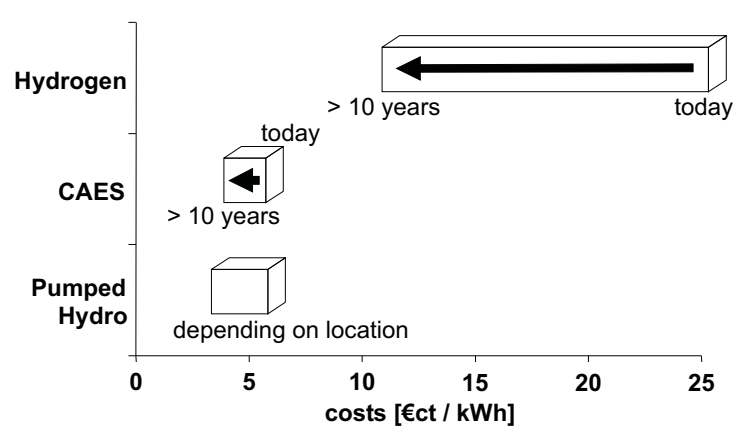

Fig. 2: Comparison of storage systems for load-leveling, class B

electrical energy to compensate the overall losses. All calculations are based on a capital cost rate of $8 \%$ /year. For CAES systems only the new adiabatic technology is taken into account. In the following, the cost figures are given as capital costs related to the electricity output of the systems.

The width can be interpreted as "state of the art" (high value) and "achievable costs" expected in 5 to 10 years, based on known technology and mass production (low value). Data from the literature, studies and expert knowledge was used for the different technologies [7]. Batteries have a significant cost reduction potential in large scale fully automated production.

For the class A application (Fig. 1), hydrogen storage can benefit from low volume related costs due to its very high energy density compared to CAES. Pumped hydro storage

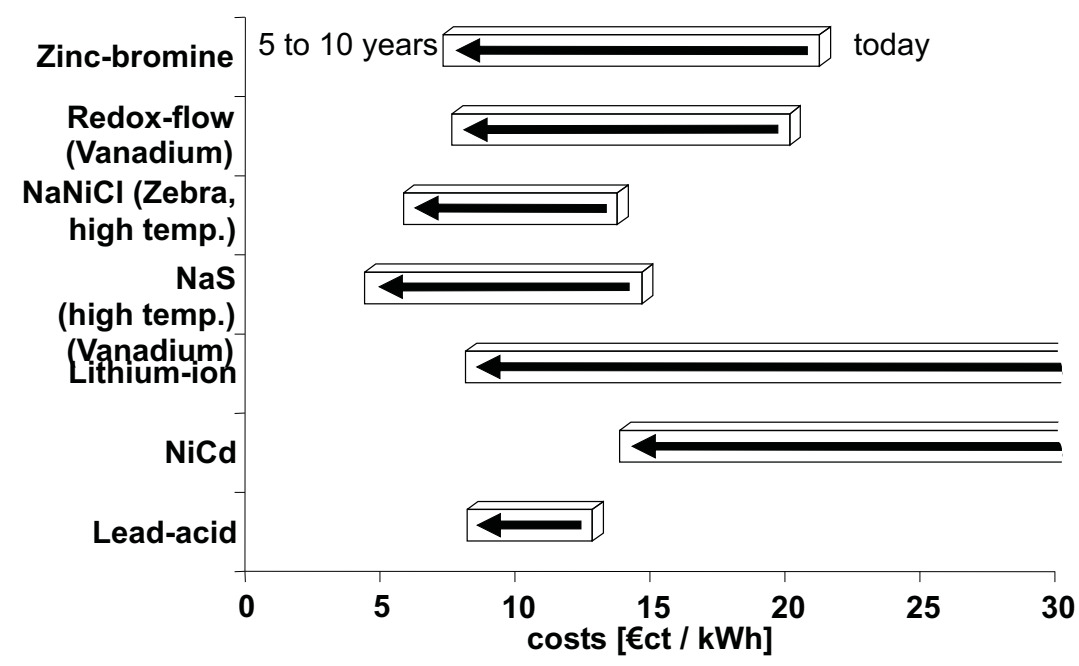

Fig. 3: Comparison of storage systems for peak-shaving at distribution level, class C 
systems could be used as long term storage at lower costs, but the technical potential for appropriate sites is very limited whereas salt cavern for hydrogen storage could be made available in sufficient quantity in suited regions.

Class B is covered today by pumped hydro power plants, which are still the most economic solution (Fig. 2). However, increasing the number of pumped hydro systems is limited by the lack of geographically suited sites and decreasing public acceptance. Compressed air stored underground in large salt caverns appears as an economically interesting and technically feasible alternative. Especially the new adiabatic CAES concepts show big advantages with regard to efficiency and ecological aspects. Battery technologies generally can be used for this application as well, centralized or decentralized. Here, the lowest costs are expected to be in the range of 8 to $12 € \mathrm{ct} / \mathrm{kWh}$. Although this is well above the costs shown in Fig. 2, it is necessary to take into account that all battery systems can also deliver primary reserve due to their very fast response time less than $10 \mathrm{~ms}$ (see also Table 1).

For storage systems of class C (Fig. 3) for medium voltage applications in the context of smart grids, supporting micro-grid or virtual power plant concepts, various electrochemical battery storage systems are competing. Regarding best-case assumptions the NaS technology is ahead at the moment. In Japan commercial applications with storage capacities up to $50 \mathrm{MWh}$ have been in operation for several years. Conventional lead-acid technology is still one of the most economic systems, although it suffers today from a very limited lifetime. With regard to battery technologies, other pros and cons also have to be discussed which cannot be expressed in terms of cost effectiveness [12].

\section{Vehicle-to-grid concepts}

Plug-in hybrids (PHEV) including the vehicle-to-grid concept (V2G) have come to attention to several major players in the energy and mobility sector just in the past two years. PHEVs with an electric driving range of 30 to $60 \mathrm{~km}$ based on 5 to $10 \mathrm{kWh}$ battery storage have become a realistic option. Electric motors, power controls, etc. are currently under development or on the market. Lithium-ion batteries show very promising results in the lab with regard to cycle lifetimes, and cost projections are good as well. If plug-in hybrids are connected with bidirectional converters to the grid (e.g. 3 to $5 \mathrm{~kW}$ power) positive and negative control power is available. A single car accounts for 3 to $5 \mathrm{~kW}$ and $10 \mathrm{kWh} .10 \%$ of the cars in Germany already offer 3 to 5 GW for 8 hours, which is in the order of all pumped hydro storage systems available for Germany. $100 \%$ of the cars in Germany can serve the full electric load for more than 3 hours. An additional advantage is the uniform distribution throughout the grid. This offers remarkable options for the control and stability of the power grid. The concept is very interesting for multiple reasons.

Car manufacturers get an option for individual mobility beyond the pure gasoline car. The average driving range per car in Germany is approx. $36 \mathrm{~km} /$ day, thus a battery with $10 \mathrm{kWh}$ would serve for a significant part of driving from electricity. On the other hand, hybrid cars still have an internal combustion engine and therefore the overall performance and range of the cars is not limited by the electrical drive.
Utilities get an additional market for electricity and at the same time also a technical solution for all problems which may arise from fluctuating power generation from wind and solar at least on a time scale of 24 hours. Significantly increased shares of electricity production become a realistic technical option based on the additional storage capacities. In addition, economic concepts show that installed storage power from plug-in hybrids can be cheaper for utilities than pumped hydro systems.

Car owners can save money when replacing gasoline by electricity, and the utilities pay for the usage of the storage systems. This can balance the additional costs for the batteries. In addition, they do not have to limit themselves with regard to the comfort of their automobile.

The environment and thus the society benefits from a significant $\mathrm{CO}_{2}$ reduction due to replacing gasoline by electricity from $\mathrm{CO}_{2}$-free power generators (renewable, coal/gas with $\mathrm{CO}_{2}$ sequestration, nuclear). This will also extend the availability of cheap oil.

The concept can work from a battery point of view, because the expected lifetime for lithium-ion batteries in the range of 5,000 cycles is sufficient for 8 years of daily electric driving plus an additional cycle for the grid. Storage systems in the grid are typically paid to be available in case of emergency (primary and secondary reserve). In fact they are needed very seldom and the real number of additional cycles will be quite small [13].

\section{Summary}

In future power supply systems, characterized by an increasing share of renewable energy resources, broad use of energy storage systems is a prerequisite in order to cope with the fluctuating nature of wind and solar energy. For long-term storage with the aim to cover also long lasting periods up to a few weeks without wind, only hydrogen, stored in salt caverns can be a technically feasible solution due to its low specific storage costs. For mid-term storage, providing control and reserve power, pumped hydro plants compete with adiabatic CAES. Although pumped hydro shows economic advantages, the construction of new plants seems to be difficult due the lack of geographically suited sites and decreasing public acceptance, whereas a sufficient number of underground salt caverns could be made available. Salt caverns built for CAES applications might be converted into a hydrogen storage system if necessary. For load-leveling applications at the distribution level, various battery technologies compete. At the time being, the lead-acid technology is still one of the most economic systems and further progress in improving the lifetime seems to be possible. New battery technologies have to be further improved in order to come to more reliable numbers with regard to investment and operation costs, as well as lifetime. At the present time, high-temperature batteries are the most interesting technology. Lithium-ion and redox-flow technologies are comparable with regard to their potential. However, the lithium-ion technology is the only one which can be considered in plug-in hybrid or full electric vehicles and within an increasing number of vehicles together with a suitable control system these cars may represent a huge storage system also to be used for grid issues (vehicle-to grid). 


\section{Acknowledgments}

The research described in the paper was supervised by Prof. Dr. Dirk Uwe Sauer, Head of the Electrochemical Energy Conversion and Storage Systems Group at the Institute for Power Electronics and Electrical Drives (ISEA), RWTH Aachen University.

\section{References}

[1] Giesecke, J., Mosony, E.: Wasserkraftanlagen - Planung, Bau und Betrieb, Berlin, Heidelberg: Springer, 1997.

[2] Heyder, B.: Energy Storage Systems in the Electricity Network, ECPE Seminar: Energy Storage Technologies, Aachen, Germany, 2007.

[3] Wietschel, M., Hasenauer, U., Vicens, N. J., Klobasa, M., Seydel, P.: Zeitschrift für Energiewirtschaft, Ein Vergleich unterschiedlicher Speichermedien für überschüssigen Windstrom, 2/2006.

[4] IPA ENERGY CONSULTING, Report to the Scottish Executive, Hydrogen technology systems, Edinburgh, Scotland, 2005.

[5] Lipman, T. E., Ramos, R., Kammen, D. M.: An Assessment of Battery and Hydrogen Energy Storage Systems Integrated with Wind Energy Resources in California, Report by the University of California, Berkeley, for the California Energy Commission, USA, 2005.

[6] Handschin, E., Styczynski, Z.: Power System Application of the Modern Battery Storage, Magdeburger Forum zur Elektrotechnik, Magdeburg, Germany, 2004.

[7] Leonhard, W., Buenger, U., Crotogino, F., Gatzen, CH., Glaunsinger, W., Huebner, S., Kleinmaier, M., Koenemund, M., Landinger, H., Lebioda, T., Sauer, D. U., Weber, H., Wenzel, A., Wolf, E., Woyke, W., Zunft, S.: ETG-Study on Energy Storage, Energiespeicher in Stromversorgungssystemen mit hohem Anteil erneuerbarere Energieträger, Power Engineering Society within VDE (ETG), Germany, 2008, www.vde.com/VDE/Fachgesellschaften/ETG.
[8] Schoenung, S. M., Hassenzahl, W. V.: Long- vs. Short-Term Energy Storage Technologies Analysis, a Life-Cycle Cost Study, Study by Sandia National Laboratories for the DOE Energy Storage Systems Program, Livermore, California, USA, 2003.

[9] Galloway, R. C., Dustmann, C.-H.: ZEBRA battery - material cost, availability and recycling, EVS20, Long Beach, California, USA, 2003.

[10] Sauer, D., Jossen, A.: Advances in Redox Flow Batteries, First International Renewable Energy Storage Conference (IRES I), Gelsenkirchen, Germany, 2006.

[11] Jonshagen, B.: The Zinc Bromine Battery for Renewable Energy Storage, First International Renewable Energy Storage Conference (IRES I), Gelsenkirchen, Germany, 2006.

[12] Kleinmaier, M., Buenger, U., Crotogino, F., Gatzen, CH., Glaunsinger, W., Huebner, S., Koenemund, M., Landinger, H., Lebioda, T., Leonhard, W., Sauer, D. U., Weber, H., Wenzel, A., Wolf, E., Woyke, W., Zunft, S.: Energy Storage for Improved Operation of Future Energy Supply Systems, CIGRE Session 2008 (International council on large electric systems), Paris, France, 2008, Paper C6-301.

[13] Sauer, D.U., Blank, T., Kowal, J., Magnor, D.: Energy Storage Technologies for Grids with High Penetration of Renewable Energies and for Grid Connected PV Systems, $23^{\text {rd }}$ European Photovoltaic Solar Energy Conference, Valencia, Spain, 2008.

Heide Meiwes

e-mail: mw@isea.rwth-aachen.de

Electrochemical Energy Conversion and Storage Systems Group

Institute for Power Electronics and Electrical Drives

(ISEA)

RWTH Aachen University

Jägerstrasse 17/19

52066 Aachen, Germany 